\title{
The quality characteristics, antioxidant activity, and sensory evaluation of reduced-fat yogurt and nonfat yogurt supplemented with basil seed gum as a fat substitute
}

\author{
Si Yeon Kim, ${ }^{1}$ O Hyeonbin, ${ }^{1}$ Phyrim Lee, ${ }^{1}$ and Young-Soon $\mathrm{Kim}{ }^{1,2 *}$ \\ ${ }^{1}$ Department of Biosystem and Biomedical Science, Korea University, 145 Anam-ro, Seongbuk-gu, Seoul 02841, Republic of Korea \\ ${ }^{2}$ Department of Food and Nutrition, Korea University, 145 Anam-ro, Seongbuk-gu, Seoul 02841, Republic of Korea
}

\begin{abstract}
This study investigated the use of basil seed gum (BSG) as a fat substitute on the physicochemical properties and antioxidant activities of yogurt. A 0.5 and 1\% BSG solution was supplemented to reduced-fat and nonfat yogurts, and their physicochemical properties, quality properties, antioxidant activity, and sensory evaluation were compared with each control group. We prepared 3 yogurts as controls and 4 yogurt samples containing BSG as follows: FFY (yogurt made from full-fat milk: a control group), LFY (yogurt made from reduced-fat milk: a control group), SY (yogurt made from nonfat milk: a control group), LFY $0.5 \%(0.5 \%$ BSG added to reduced-fat yogurt), LFY $1.0 \%(1.0 \%$ BSG added to reduced-fat yogurt), SY $0.5 \%(0.5 \%$ BSG added to nonfat yogurt), and SY 1.0\% (1.0\% BSG added to nonfat yogurt). The $\mathrm{pH}$ of LFY $0.5 \%$ and LFY $1.0 \%$ was decreased compared with LFY control, whereas pH of SY $0.5 \%$ and SY $1.0 \%$ had no significant difference. The titratable acidity showed no significant increase. The viscosity was the highest in FFY among the control groups and increased with the concentration of BSG in the SY group. The $L$-value (brightness) and $b$-value (yellowness) were the highest in FFY at 85.05 among the control groups. The $L$-value and $b$ value of LFY $0.5 \%$ and SY $0.5 \%$ showed higher values than LFY $1 \%$ and SY $1 \%$. The $a$-value (redness) was the highest in SY $0.5 \%$ at -2.36 , and $\Delta E$ (total color difference) was the highest in SY $1 \%$ at 7.33 . The moisture content of SY was the highest among the control groups and addition of 1\% BSG to SY was highest among the BSG-added group. Total contents of phenol and flavonoid slightly increased as the concentration of BSG increased (increase in the contents of phenol and flavonoid). The results of ferric reducing antioxi-
\end{abstract}

Received June 17, 2019.

Accepted October 10, 2019.

*Corresponding author: kteresa@korea.ac.kr dant power were similar to the findings of phenol and flavonoid content (an increase as the concentration of BSG increased). The overall acceptability of sensory characteristics was improved in all groups of samples when BSG 1\% concentration increased. Application of BSG for the production of nonfat yogurt can enhance physicochemical properties, antioxidant activity, and sensory characteristics of reduced-fat and nonfat yogurt. Addition of BSG to reduced-fat and nonfat yogurt can improve their physical and antioxidant properties to the level of FFY.

Key words: antioxidant activity, basil seed gum, reduced-fat yogurt, quality property, sensory evaluation

\section{INTRODUCTION}

Yogurt occupies a large portion in the dairy product market and is prepared by lactic acid fermentation of milk. Yogurt has a known high nutritional value and contains proteins, fat, and essential minerals. Nonetheless, milk fat is associated with several diseases [e.g., obesity, elevated blood pressure, heart disease, and some cancers (Sandoval-Castilla et al., 2004; Fu et al., 2018)]. Tamime and Deeth (1980) reported that the main purpose of purchasing a dairy product is to maintain health and the main requirements for good dairy products are functional properties, storage stability, and low calorie content. According to recent dairy product trends, the demand for yogurt with little or no fat is increasing (Olivares et al., 2019). Furthermore, consumers are interested in reduced-fat or nonfat products that still have sensory characteristics similar to conventional quality properties of full-fat dairy products (Verbeke, 2006). However, the reduction of fat content (reduced-fat yogurt and nonfat yogurt) affects flavor, texture, and structure and causes a reduction of TS content so that the final product has weak consistency and poor texture. Especially in yogurt, which appears as a weak gel, the reduction of fat content causes phase separation and syneresis by decreasing water-holding capacity (WHC) and resulting in quasi-stable struc- 
ture (Tamime and Robinson, 1999; Laiho et al., 2017). To compensate for the fat reduction, the most common strategies involve a fat substitute substance or stabilizer (Sandrou and Arvanitoyannis, 2000). Many fat substitutes such as the use of carbohydrates, protein, fat, or synthetic substances have been applied to improve the quality properties of nonfat or reduced-fat yogurt (Arancibia et al., 2011). Previous studies investigated fat substitute substances in nonfat yogurt [e.g., inulin (Guven et al., 2005), tragacanth gum (Aziznia et al., 2008), glucomannan (Dai et al., 2016), and salecan (Fu et al., 2018)]. Supplementation of inulin at more than $1 \%$ causes separation of whey but $\mathrm{pH}$ and titratable acidity (TTA) are not influenced, and there is also a decrease in sensory properties (Guven et al., 2005). Other studies have also shown that addition of more than $1 \%$ has a negative effect on yogurt.

Basil seed (Ocimum L.) comes from a plant that is a member of the Labiatae family. Basil seed is known as a flavoring agent and has antioxidant, antiseptic, antiaging, anti-inflammatory, and antimicrobial activities (Karthikeyan et al., 1999). Besides, the basil seed gum (BSG) has been reported to have antiobesity properties as determined by measuring the inhibitory activity toward protein tyrosine phosphatase 1B. Basil seed gum is an outer pericarp separated from basil seed (Karthikeyan et al., 1999). When basil seed is hydrated, it turns into a gelatinous mass composed of a mucilaginous layer containing a large content of unesterified galacturonic acid with high WHC (Naji-Tabasi and Razavi, 2017a). Basil seed gum contains polysaccharides $(2,320 \mathrm{kDa})$ and is classified into 2 fractions: PER-BSG, which has higher molecular weight $(5,980$ $\mathrm{kDa}$ ) and is the bulk of BSG (69\%); and SUPER-BSG, which has lower molecular weight $(1,045 \mathrm{kDa})$ and represents a smaller proportion (31\%; Naji-Tabasi et al., 2016). It is reported that BSG has shear-thinning properties and is stable under yield stress (Imam et al., 2012). Osano et al. (2014) reported that a BSG solution $(0.1-1.0 \%$, wt/wt) can reduce surface tension owing to high molecular weight and can act, for example, as an emulsifying agent, foaming agent, suspending agent, gelling agent, and fat replacer (Naji-Tabasi and Razavi, 2016, 2017a). As a fat replacer, BSG, which has a fatlike structure, provides crucial properties of fat (WHC, sensory properties) and improves texture properties of food (Naji-tabasi and Razavi, 2017a). Despite these various properties, no study has been done on the utilization of BSG in the production of reduced-fat and nonfat yogurt.

In this study, BSG was supplemented to reduced-fat milk, and nonfat milk to produce reduced-fat or nonfat yogurt to investigate the suitability of BSG as a fat substitute substance. We measured quality character- istics and antioxidant activities and evaluated sensory characteristics to determine the optimal proportion of BSG in yogurt.

\section{MATERIALS AND METHODS}

\section{Materials}

Milk, reduced-fat milk, and nonfat milk (Meil Milk Ltd., Yang-Ju, Korea) were purchased at a local market. The contents of protein and fat in full-fat milk, reduced-fat milk, and nonfat milk were $3.0 \mathrm{~g} / 100 \mathrm{~mL}$ (for all) and 4.0, 1.0, and $0 \mathrm{~g} / \mathrm{mL}$, respectively. Basil seed was obtained from Seohyun Pharmaceutical Farming Association Co. Ltd. (Nonsan, Korea), and yogurt starter was purchased from Hurum Ltd. (Cheongone, Korea).

\section{Extraction of BSG}

To extract basil gum from basil seeds, the method of Hosseini-Parvar et al. (2010) with a slight modification was performed. The extraction process was carried out by a juice extractor (NJE-3530, NUC, Daegu, Korea) as follows: BSG was prepared by soaking under water at a temperature of $69^{\circ} \mathrm{C}$ and $\mathrm{pH} 8$, and the total water/seed ratio was 65:1. Before the sample was used in the experiment, BSG was freeze-dried for $96 \mathrm{~h}$ and then pulverized in a high-speed grinder. Then, BSG solutions (0.5 and $1.0 \%$ ) were prepared by dissolving BSG powder in distilled water and stored for $24 \mathrm{~h}$ at $4^{\circ} \mathrm{C}$ before yogurt production.

\section{Yogurt Preparation}

Yogurt was made by using fermentation machine (SYF-6400, Samyang, Gunpo, Korea). The yogurt formula was devised on the basis of the studies where yogurt was made with the addition of glucomannan as a fat substitute substance (Dai et al., 2016; Table 1). Yogurt mixtures were heated at $85^{\circ} \mathrm{C}$ for $30 \mathrm{~min}$, then mixed with each BSG solution and yogurt starter and cooled for $40 \mathrm{~min}$ to $45^{\circ} \mathrm{C}$. The sample solutions were fermented in a plastic bottle $(6.5 \times 6.5 \times 9 \mathrm{~cm})$ for $8 \mathrm{~h}$ at $45^{\circ} \mathrm{C}$ then cooled in a refrigerator $\left(4^{\circ} \mathrm{C}\right)$ for $4 \mathrm{~h}$. The samples were prepared with different concentrations of BSG and were designated as follows: FFY (yogurt made from full-fat milk: a control group), LFY (yogurt made with reduced-fat milk: a control group), SY (made with nonfat milk: a control group), LFY $\mathbf{0 . 5 \%}$ (0.5\% BSG added to reduced-fat yogurt), LFY $\mathbf{1 . 0 \%}$ (1.0\% BSG added to reduced-fat yogurt), SY $\mathbf{0 . 5 \%}$ (0.5\% BSG added to nonfat yogurt), and SY $\mathbf{1 . 0 \%}$ (1.0\% BSG added to nonfat yogurt). 


\section{Fat Content}

The fat content was measured according to AOAC (1990) methods with some modifications. Twenty grams of a sample was freeze-dried for $24 \mathrm{~h}$. The samples were mixed with $200 \mathrm{~mL}$ of n-hexane, and then passed through Whatman no. 1 filter paper (GE Healthcare, Little Chalfont, UK). Three replicates were prepared for each sample, and the filtered solution was analyzed after removal of the solvent at $60^{\circ} \mathrm{C}$ in a rotary evaporator. The following formula was used to calculate the fat content:

Fat content $(\%)=($ sample weight after extraction

- sample weight before extraction)/

initial sample weight $\times 100$.

\section{pH and TTA Measurement}

To determine $\mathrm{pH}$ of each sample, $10 \mathrm{~g}$ of a sample was mixed with $90 \mathrm{~mL}$ of distilled water in a $250-\mathrm{mL}$ beaker and homogenized (Unidrive 1000D, CAT M. Zipperer GmbH, Staufen, Germany) for $1 \mathrm{~min}$. The $\mathrm{pH}$ of the solution was measured after $15 \mathrm{~min}$. To measure TTA of yogurts, the titration method of AOAC (1990) was used. Ten grams of a yogurt sample was diluted with $90 \mathrm{~mL}$ of distilled water, and we took $20 \mathrm{~g}$ of this solution. We dropped phenolphthalein into the solution and then titrated it using $0.1 \mathrm{~N} \mathrm{NaOH}$. The TTA was calculated using the following formula:

$$
\operatorname{TTA}(\%)=(\mathrm{a} \times \mathrm{f} \times 0.009 / \mathrm{W}) \times 100,
$$

where a is the volume of $0.1 \mathrm{~N} \mathrm{NaOH}(\mathrm{mL}), \mathrm{f}$ is the factor of $0.1 \mathrm{~N} \mathrm{NaOH}(\mathrm{mL}), \mathrm{W}$ is the weight of the sample, and 0.009 is the lactic acid amount equivalent to $1 \mathrm{~mL}$ of $0.1 \mathrm{~N} \mathrm{NaOH}$.

\section{Moisture Content}

The moisture content of each sample was measured using a moisture analyzer (MB35, OHAUS, Zurich, Switzerland). A 5-g aliquot was taken from each sample. Three replicates were prepared for each sample.

\section{Color}

To measure the color of samples, the surface of each sample was evaluated according to Hunter's color value system. The $L$ (brightness), $a$ (redness), and $b$ (yellowness) were measured by colorimeter (CR-400, Konica Minolta, Osaka, Japan) next. To calculate the value of $\Delta E$ (total color difference), the following formula was used:

$\Delta E=$

$\sqrt{\left(L_{\text {sample }}-L_{\text {standard }}\right)^{2}+\left(a_{\text {sample }}-a_{\text {standard }}\right)^{2}+\left(b_{\text {sample }}-b_{\text {standard }}\right)^{2}}$,

where $\Delta L, \Delta a$, and $\Delta b$ are the differences in $L, a$, and $b$ values between the calibration white board $(L: 96.62, a$ : $-0.04, b: 1.63)$ and a sample, respectively. The National Bureau of Standards (NBS unit), which is determined by the difference of $\Delta E$ classified as $0-0.5$ (trace), 0.5 1.5 (slight), 1.5-3.0 (noticeable), 3.0-6.0 (appreciable), 6.0-12.0 (much), or 12.0 or more (very much) according to the method of Nimeroff (1968). The NBS unit was evaluated according to the following equations:

$$
\text { NBS unit }=\Delta E \times 0.92 .
$$

\section{Viscosity}

This parameter was determined according to the method of Shihata and Shah (2002) with some modifications. The samples were analyzed with spindle No. 4 rotation at $60 \mathrm{rpm}$ using a viscometer (LVDV-1 prime,

\begin{tabular}{|c|c|c|c|c|c|c|}
\hline \multirow[b]{2}{*}{ Item } & \multicolumn{6}{|c|}{ Yogurt mix composition } \\
\hline & $\begin{array}{l}\text { FFM } \\
(\mathrm{mL})\end{array}$ & $\begin{array}{l}\text { LFM } \\
(\mathrm{mL})\end{array}$ & $\begin{array}{l}\text { SM } \\
(\mathrm{mL})\end{array}$ & $\begin{array}{l}\text { Water } \\
(\mathrm{mL})\end{array}$ & $\begin{array}{c}0.5 \% \mathrm{BSG} \\
\text { solution }(\mathrm{mL})\end{array}$ & $\begin{array}{c}1 \% \mathrm{BSG} \\
\text { solution }(\mathrm{mL})\end{array}$ \\
\hline FFY & 28.5 & & & 1.5 & & \\
\hline LFY & & 28.5 & & 1.5 & & \\
\hline SY & & & 28.5 & 1.5 & & \\
\hline LFY $0.5 \%$ & & 28.5 & & & 1.5 & \\
\hline LFY 1\% & & & 28.5 & & & 1.5 \\
\hline SY $0.5 \%$ & & 28.5 & & & 1.5 & \\
\hline SY 1\% & & & 28.5 & & & 1.5 \\
\hline
\end{tabular}

Table 1. Yogurt composition before fermentation ${ }^{1}$ 
Brookfield Engineering Labs Inc., Middleboro, MA). The values were recorded during a $40 \mathrm{~s}$ measurement period in millipascal seconds ( $\mathrm{mPa} \cdot \mathrm{s})$. For each sample, we prepared 12 replicates.

\section{WHC}

According to the method of Sahan et al. (2008), to measure the $\mathrm{WHC}$ of yogurt, 5 -g yogurt samples were centrifuged at $4,000 \times g$ for $30 \mathrm{~min}$ at $4^{\circ} \mathrm{C}$ in a centrifuge (Universal 32R, Hettich, Tuttlingen, Germany). Three replicates were prepared for each sample during storage $(0,5,10$, and $15 \mathrm{~d})$ and the WHC was calculated using the following formula:

$$
\begin{aligned}
\text { WHC }(\%)= & {[\text { precipitate }(\mathrm{g})-\text { sample }(\mathrm{g})] / } \\
& \text { sample }(\mathrm{g}) \times 100 .
\end{aligned}
$$

\section{Syneresis}

To measure the syneresis of yogurt samples, the method of Lucey et al. (1998) was performed with some modifications. A 25-g aliquot of each sample was placed on a funnel that was covered with Whatman filter paper no. 1 and filtered during storage $(0,5,10$, or 15 d) at $4^{\circ} \mathrm{C}$. The syneresis was expressed as the percent weight of the whey separated from the initial sample and calculated using the following formula:

$$
\begin{gathered}
\text { Syneresis }(\%)=[\text { separated whey }(\mathrm{g}) / \\
\text { initial sample weight }(\mathrm{g})] \times 100 .
\end{gathered}
$$

Three replicates were prepared for each sample.

\section{Extraction of Samples}

A total of $1 \mathrm{~g}$ of each sample was extracted for $3 \mathrm{~h}$ with $9 \mathrm{~mL}$ of distilled water by means of a water bath. Centrifugation was performed for $30 \mathrm{~min}$ at $4,000 \times$ $g$ and $4^{\circ} \mathrm{C}$ in the centrifuge (Universal 32R, Hettich, Tuttlingen, Germany), and the samples were passed through Whatman no. 1 filter paper.

\section{Determination of Total Phenol Content}

The total polyphenol content was analyzed using the method of Folin-Denis with a slight modification, as suggested by Akay et al. (2011). A solution containing $0.9 M$ Folin-Ciocalteu reagent (Junsei Chemistry, Tokyo, Japan) and a 20\% (wt/vol) sodium carbonate solution (Merck KGaA, Darmstadt, Germany) were prepared. Then, $10 \mu \mathrm{L}$ of each sample was vortexed with $790 \mu \mathrm{L}$ of distilled water for $1 \mathrm{~min}$. A total of 50 $\mu \mathrm{L}$ of $0.9 \mathrm{~N}$ Folin-Ciocalteu reagent (Junsei Chemistry) was added to $150 \mu \mathrm{L}$ of the $20 \%$ sodium carbonate solution (Merck KGaA) and then incubated for $30 \mathrm{~min}$ at room temperature in the dark. The absorbance of each sample was measured at $750 \mathrm{~nm}$ wavelength on a microplate reader (Infinite 200 PRO, Tecan, Mannedorf, Switzerland). Gallic acid (Merck KGaA) served as a standard, and the absorbance of each sample was converted to gallic acid equivalents.

\section{Determination of Flavonoid Content}

The flavonoid content was measured as previously described by Vosoughi et al. (2018) with slight modifications. A total of $1 \mathrm{~mL}$ of each sample was vortexed with $150 \mu \mathrm{L}$ of $5 \%$ sodium nitrite (Junsei Chemistry) for 6 min in the dark $\left(25^{\circ} \mathrm{C}\right)$, followed by the addition of 300 $\mu \mathrm{L}$ of $10 \%$ aluminum chloride (Junsei Chemistry) and incubation in the dark $\left(25^{\circ} \mathrm{C}\right)$ for 5 min. The solution was reacted with $1 \mathrm{~mL}$ of $1 \mathrm{~N}$ sodium hydroxide solution (Daejung Chemicals \& Metals, Gyeonggi, Korea). Absorbance of each sample was analyzed at $520 \mathrm{~nm}$. Absorbance calibration curves were constructed using quercetin (Sigma-Aldrich, St. Louis, MO) as a standard, and the total flavonoid content of each sample was converted to quercetin equivalents.

\section{Determination of Antioxidant Capacity: Ferric Reducing Antioxidant Power Assay}

Ferric reducing antioxidant power (FRAP) was measured by the method of Benzie and Strain (1996) with some modifications. The reagents included $0.2 \mathrm{M}$ phosphate buffer ( $\mathrm{pH} 6.6), 1 \%$ potassium ferricyanide (Merck KGaA), $10 \%$ trichloroacetic acid (SigmaAldrich), and $0.1 \%$ ferric chloride $\left(\mathrm{FeCl}_{3}\right)$ (Junsei Chemistry). A total of $250 \mu \mathrm{L}$ of a sample and $250 \mu \mathrm{L}$ of $0.2 \mathrm{M}$ phosphate buffer and $1 \%$ potassium ferricyanide were allowed to react for $30 \mathrm{~min}$ at $50^{\circ} \mathrm{C}$, and the mixture was reacted with $250 \mu \mathrm{L}$ of $10 \%$ trichloroacetic acid. A total of $0.5 \mathrm{~mL}$ of this mixture was mixed with $0.5 \mathrm{~mL}$ of distilled water and $0.1 \% \mathrm{FeCl}_{3}$. The absorbance of each solution was measured at $700 \mathrm{~nm}$.

\section{Sensory Evaluation}

A panel of 40 individuals (untrained; 22 females and 18 males; aged 23 to $31 \mathrm{yr}$, free of lactose intolerance), consisting of graduate students and staff of the Korea University, participated and were trained on how to perform sensory evaluation. Approximately $1 / 4$ of the panelists $(12 / 40)$ were regular consumers of dairy products (once a day), and $2 / 4$ of the panelist $(18 / 40)$ were occasional consumers who consume a dairy product once a week. The other panelists were general consum- 
ers who consume a dairy product 3 times a week. Yogurt samples were prepared and labeled with random number. The panels received 7 samples in a plastic cup $(5 \mathrm{~mL})$ on a white plate. In this sensory evaluation test, we analyzed the appearance, flavor, texture, sweetness, and overall acceptability of the samples on a 9-point scale (strongly dislike $=1$ and strongly like $=9$ ).

\section{Statistical Analysis}

All data were expressed as the mean \pm standard deviation of triplicate experiments. All data obtained from measurements were evaluated by one-way ANOVA in SPSS, ver. 23.0 (IBM Corp., Armonk, NY). Significance of a difference between the means of measured experimental values was analyzed by Duncan's multiple-range test $(P<0.05)$.

\section{RESULTS AND DISCUSSION}

\section{Fat Content, Moisture Content, $\mathrm{pH}$, and TTA}

The determined fat content is shown in Table 2 and showed slight differences among the samples. The FFY had the highest fat content, whereas SY, SY $0.5 \%$, and SY $1 \%$ had the lowest fat content among the samples $(P<0.001)$. The moisture content of yogurts was influenced by the contents of protein and fat: a decrease in milk fat content has been linked to an increase in moisture content because of an increase in the total amount of soluble minerals (Madadlou et al., 2005). The results of moisture content is shown in Table 2. The moisture content of FFY was the lowest among the control groups, and that of SY 1.0\% was the highest among all the samples $(P<0.001)$. The BSG-supplemented groups were found to have higher moisture content than the control groups $(P<0.001)$. The result on $\mathrm{pH}$ and TTA of yogurts are summarized in Table 2. The $\mathrm{pH}$ and TTA of yogurt are affected, for example, by TS content, $\mathrm{pH}$, and temperature of fermentation (Tamime and Deeth, 1980). Tamime and Deeth (1980) reported that the most suitable $\mathrm{pH}$ of yogurt is in the range of 3.7 to 4.7 . The $\mathrm{pH}$ levels of the yogurt samples ranged from 4.17 to 4.36 , and $\mathrm{pH}$ was decreased with the addition of BSG. Jenness and Patton (1959) stated that the increase of TS leads to a decrease in $\mathrm{pH}$ and an increase in TTA owing to the buffering action of the milk constituents. The $\mathrm{pH}$ of the BSG-supplemented yogurts was slightly lower than that of control groups $(P<0.001)$. The $\mathrm{pH}$ of LFY $0.5 \%$ and LFY $1 \%$ were slightly decreased, but the pH of SY $0.5 \%$ and SY $1 \%$ did not show significant difference $(P<0.001)$. This result is similar to these previously obtained with addition of glucoman- nan (Dai et al., 2016) and inulin (Guven et al., 2005) as a fat substitute substance in yogurts (there was no significant difference between the samples; $P<0.001$ ). However, Aziznia et al. (2008) found that the addition of whey protein concentrate and gum tragacanth as a fat substitute substance affects $\mathrm{pH}$ of yogurt: as the amount of the replacer increased, $\mathrm{pH}$ decreased. These results are consistent with the observation reported by Lucey et al. (1998) that an increase of fat content leads to a $\mathrm{pH}$ increase because of lactic acid bacteria growth and activity. Several other studies such as Sahan et al. (2008) and Brennan and Tudorica (2008) showed that $\mathrm{pH}$ increased when the fat content of yogurts increased. Furthermore, $\mathrm{pH}$ significantly influences the ability to form a gel of BSG that when $\mathrm{pH}$ is closer to acidic, the rate of gel formation is faster and gives elasticity to the gel in contrast to an alkaline condition (Naji-Tabasi and Razavi, 2017b). The TTA values of the LFY, LFY $0.5 \%$, and LFY $1.0 \%$ were not affected by different levels of fat content and did not show significant differences among the samples; however, the SY group was higher than SY $0.5 \%$ and SY $1.0 \%(P<0.001)$. In this study, the TTA of samples $(0.70-0.89 \%)$ was in the TTA range of good-quality yogurt $(0.36-1.11 \%)$ as suggested by Lee and Lucey (2010). The results of our study are in agreement with that from addition of guar gum (Milani and Koocheki, 2011). Yazici and Akgun (2004) reported that the higher TTA value was due to the moisture content of reduced-fat yogurt and nonfat yogurt even though there was not a significant difference between the samples $(P<0.001)$.

\section{Color}

Dai et al. (2016) demonstrated that the color is an important parameter of food choice by consumer panelists. Hunter scale $(L, a, b)$ is used to measure the color of food and is more sensitive to $a$-value (redness) and $b$-values (yellowness) than $L$-value (whiteness; Becerir, 2017). The results from our samples are shown in Table 2 and Figure 1 . The $L$-value was slightly different: the control groups showed a higher value than did other groups $(P<0.001)$. A slight difference was seen among the control groups and FFY, which had the highest fat content, yielded the highest $L$-value $(P<0.001)$. These results indicate that the addition of BSG increases darkness of yogurt samples relative to the control group and that fat content also influences the $L$-value. As the concentration of BSG increased, the $L$-value decreased, whereas when the content of fat increased, the $L$-value increased. The $a$-value and $b$-value slightly increased in the BSG-supplemented groups when the concentration of BSG in the yogurt samples increased $(P<0.001)$. The differences in $a$-value and $b$-value shows that the 


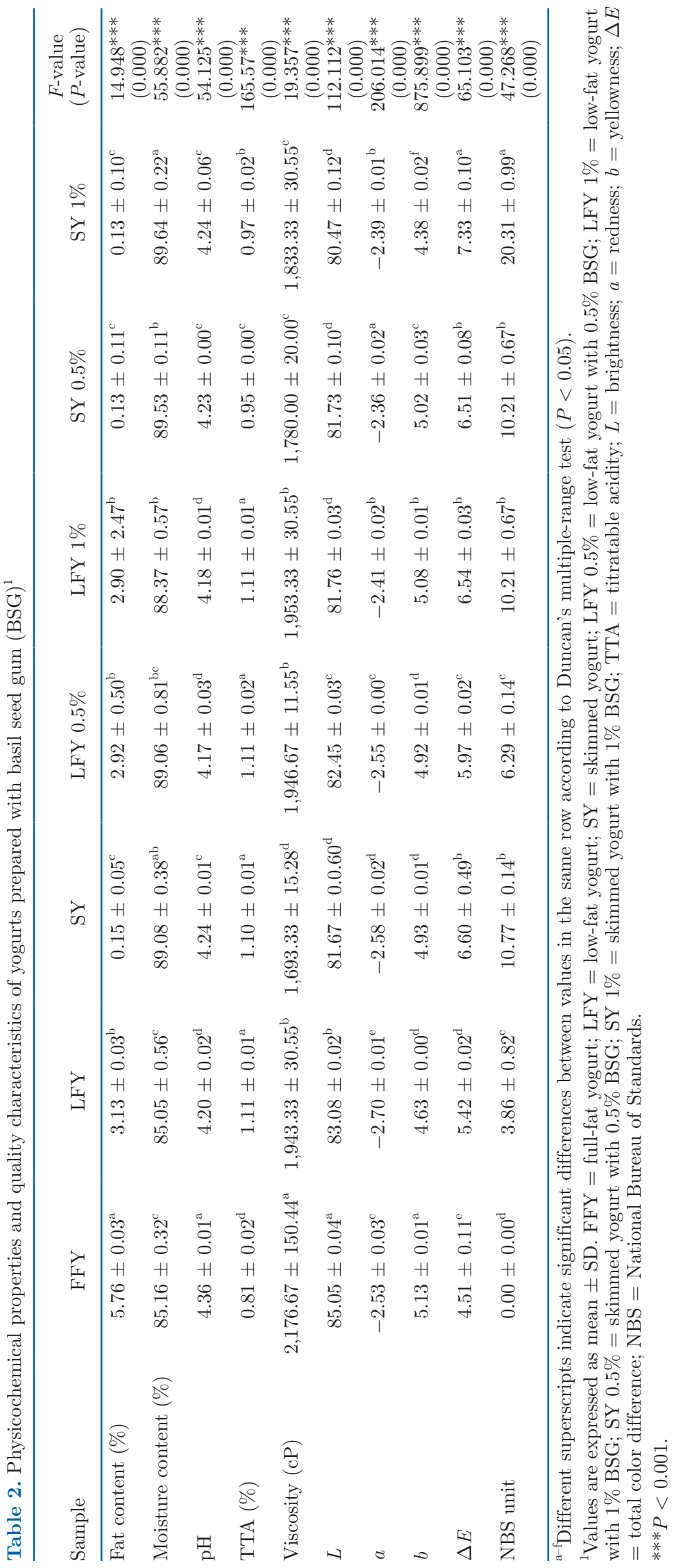


addition of BSG to yogurt gives a slight color difference to the samples according to BSG concentration $(P<0.001)$. Our results for the $a$-value and $b$-value are similar to the findings from addition of wholebarley flour (Lee et al., 2015) but slightly different from the addition of glucomannan (Dai et al., 2016) and $\beta$-glucan (Brennan and Tudorica, 2008), where the $b$-value decreased as the concentration of a fat substitute substance increased. Furthermore, the total color difference $(\Delta E)$ slightly increased as the concentration of BSG increased. Classification of the values based on NBS unit, which was compared with FFY, determined the following differences: LFY (appreciable), SY (much), LFY 0.5\% (much), LFY 1\% (much), SY 0.5\% (much), and SY 1\% (very much). We observed that the original color of the full-fat milk that we used in this study was $L: 83.77, a:-2.73$, and $b: 5.19$; that of reduced-fat milk was $L: 76.70, a:-3.64$, and $b: 2.65$; the color of nonfat milk was $L: 69.20, a:-4.20$, and $b$ : 1.23 ; that of the $0.5 \%$ solution of BSG was $L: 54.00, a$ : -0.07 , and $b: 6.02$; and the color of the $1 \%$ solution of BSG was $L: 51.00, a: 0.56$, and $b: 8.33$. This color difference in original ingredients affected the yogurt color: the final colors of BSG-supplemented yogurt samples were different from the color of control groups.

\section{Viscosity}

The stability of textural properties, which are evaluated as viscosity, firmness, amplitude sweep, adhesiveness, gumminess, springiness, and cohesiveness among others, is the main indicator of yogurt rheological properties (Guven et al., 2005). Texture stability is influenced by TS, contents of fat and protein, $\mathrm{pH}$, acidity, temperature, homogenization, and processing method (Rasic and Kurmann, 1978). The viscosity is one of the most important textural properties (Mudgil et al., 2018). Rafe et al. (2013) reported that BSG contains fibrils that have a globular structure resembling scattered cotton. Due to the properties of BSG structure, BSG gives shear-thinning properties, and the viscosity of BSG is highly dependent on concentration, $\mathrm{pH}$, ionic strength, temperature, and absence of salt (Razavi et al., 2009; Hosseini-Parval et al., 2010). Significant variation was seen in viscosity, and the viscosity of yogurt samples is presented in Table 2. The FFY had the highest viscosity, and other groups had lower viscosity than the BSG-supplemented groups $(P<0.001)$. The addition of BSG maintains the viscosity of LFY and the viscosity of SY $0.5 \%$ and SY $1 \%$ were higher than $\mathrm{SY}$; also, as the concentration of BSG increased the viscosity increased $(P<0.001)$. The skimmed yogurt containing BSG showed significantly more viscous solution than that of control. Similar results were reported for low-calorie pistachio butter supplemented with BSG and xanthan gum (Emadzadeh et al., 2015), for reduced-fat mayonnaise supplemented with BSG (Razavi et al., 2012), and for reduced-fat ice cream (Javidi et al., 2016), where BSG increased viscosity and gave a stiffer texture relative to a control group. Razavi and Naji-Tabasi (2017) reported that the viscosity of BSG showed similar rheology to that of xanthan gum, and Brennan and Tudorica (2008) found that reduced-fat yogurt supplemented with $\beta$-glucan showed increased viscosity, similar to the findings in our study. However, addition of glucomannan (Dai et al., 2016) to yogurt did not affect viscosity index values, and a study on inulin added to yogurt (Ramchandran and Shah, 2009) revealed that the addition of inulin did not influence the firmness and viscosity of yogurt. Rafe et al. (2013) found that when BSG is added to a protein gel, the globular proteins are reconnected to each other by the thin fibrils of BSG and develop a bicontinuous microstructure where the size of aggregates is smaller than that in the initial gel.

\section{WHC}

Water-holding capacity is expressed as the percentage of whey separated from the gel by centrifugal force, and the centrifugation method was used to measure WHC (Amatayakul et al., 2006). Water-holding capac-

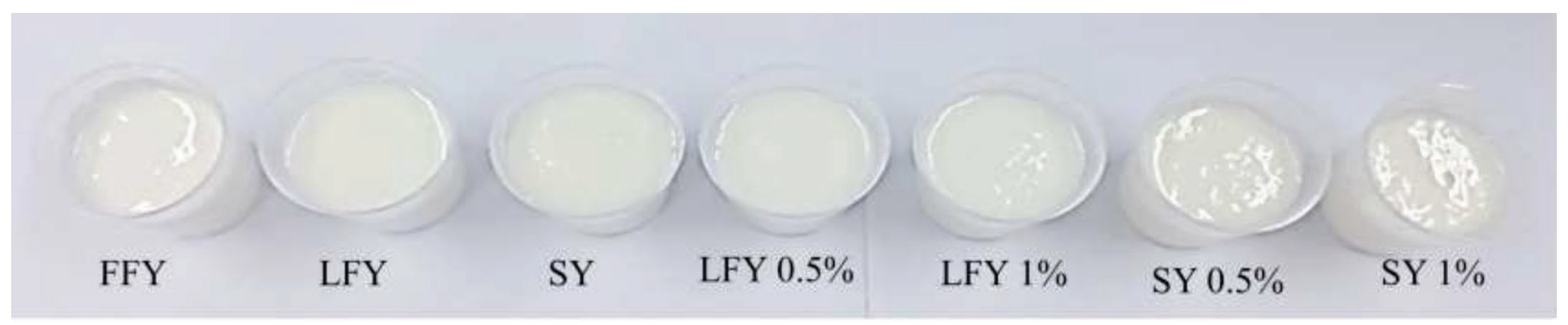

Figure 1. A photograph of yogurts prepared with basil seed gum (BSG). FFY = full-fat yogurt; LFY = low-fat yogurt; SY = skimmed yogurt; LFY $0.5 \%=$ low-fat yogurt with $0.5 \%$ BSG; LFY $1 \%=$ low-fat yogurt with $1 \%$ BSG; SY 0.5\% = skimmed yogurt with $0.5 \%$ BSG; SY $1 \%=$ skimmed yogurt with $1 \%$ BSG. 
ity is a parameter of the capacity for absorption of water, and WHC external force is applied to measure WHC (Coorey et al., 2014). This external force causes a phase separation between the protein and polysaccharide, which leads to a change in rheological properties and rigidity of yogurt gels (Amatayakul et al., 2006). Dai et al. (2016) reported that higher WHC leads to less whey separation from yogurt. The BSG has high WHC that can be used for designing new formulations and modifications of the original formulations (Kadam et al., 2012). Furthermore, BSG solutions give thixotropy properties to another solution by creating a 3 -dimensional structure that is called a fat-like structure (Naji-Tabasi and Razavi, 2017a). As the concentration of BSG increased, the network of gel became finer and the pores became smaller, thus allowing water to become entrapped and making the gel harder and stiffer (Rafe et al., 2013). Mistry and Hassan (1992) reported that denser structure and lower porosity give yogurt greater water-retention capacity. The WHC of FFY was the highest, and that of SY was the lowest among the control groups (Figure 2). There was a slight correlation with storage period: overall WHC slightly increased during storage. The WHC of FFY was the highest during d 15 of storage. The WHC of LFY was higher than LFY $0.5 \%$ and LFY $1 \%$, whereas SY was lower than the SY $0.5 \%$ and SY $1 \%$ at d 0 . At d 5 , LFY $0.5 \%$ shows the lowest value among the LFY group, but the LFY $1 \%$ was higher than LFY. The SY $0.5 \%$ was the lowest among the SY group, but SY $1 \%$ shows a higher value than SY. The addition of BSG $0.5 \%$ to LFY did not have a positive effect, whereas the addition of BSG $1 \%$ increased the WHC of LFY at d 10 and 15. At d 10, as the concentration of BSG increased the WHC was increased in SY samples. However at d 15, WHC of SY was highest among the SY group so that the addition of BSG did not improve the WHC of yogurts. As compared with the control groups, fat content influenced the WHC; namely, as the content of fat increased, WHC increased, although Akgun et al. (2016) reported no correlation between fat content and WHC and syneresis of buffalo milk yogurt. However, reduced-fat content can cause whey separation due to the weak structure. This is because fat increases WHC, which can improve the interaction of casein and fat globule membranes (Tamime and Robinson, 2007). Different results were obtained with addition of glucomannan (Dai et al., 2016), $\beta$-glucan (Sahan et al., 2008), and gum tragacanth (Aziznia et al., 2008) where there was no increase in the WHC of reduced-fat and nonfat yogurt and there was no significant correlation with storage time. Aziznia et al. (2008) explained that the addition of tragacanth gives yogurt a more open structure and decreases WHC. Also, Akgun et al. (2016) reported that the decrease of $\mathrm{pH}$ and higher fat content cause the ionic equilibrium of the gel matrix, which can maintain stable gel formation. The high water-binding capacity of BSG is the reason why BSG increased WHC in yogurts in our study. Furthermore, the difference in the $\mathrm{pH}$ and the content of fat may affect the results. The BSG makes yogurt structure finer and can entrap more water; this may be the reason why BSG increased WHC in yogurts in this study.

\section{Syneresis}

The principle that was used in this study is acceleration of the separation between milk protein and polysaccharides by gravity (Dai et al., 2016). The results on syneresis were similar to the results on WHC (Figure 3). Akgun et al. (2016) found that TS content (protein and fat), milk composition, and acidity influence syneresis, namely, that an increase in solids content reduces pore size and results in a finer structure of the yogurt gel. The protein and fat have fairly high $\mathrm{WHC}$, and $\mathrm{pH}$ affects syneresis where alkaline $\mathrm{pH}$ may result in larger pores and then cause an increase in syneresis (Song et al., 2017). The FFY and LFY had the lowest and SY had the highest syneresis among the controls during storage (Figure 3). Due to the content of TS, which can result in a denser structure of yogurt, FFY had the lowest syneresis. The syneresis increased rapidly from

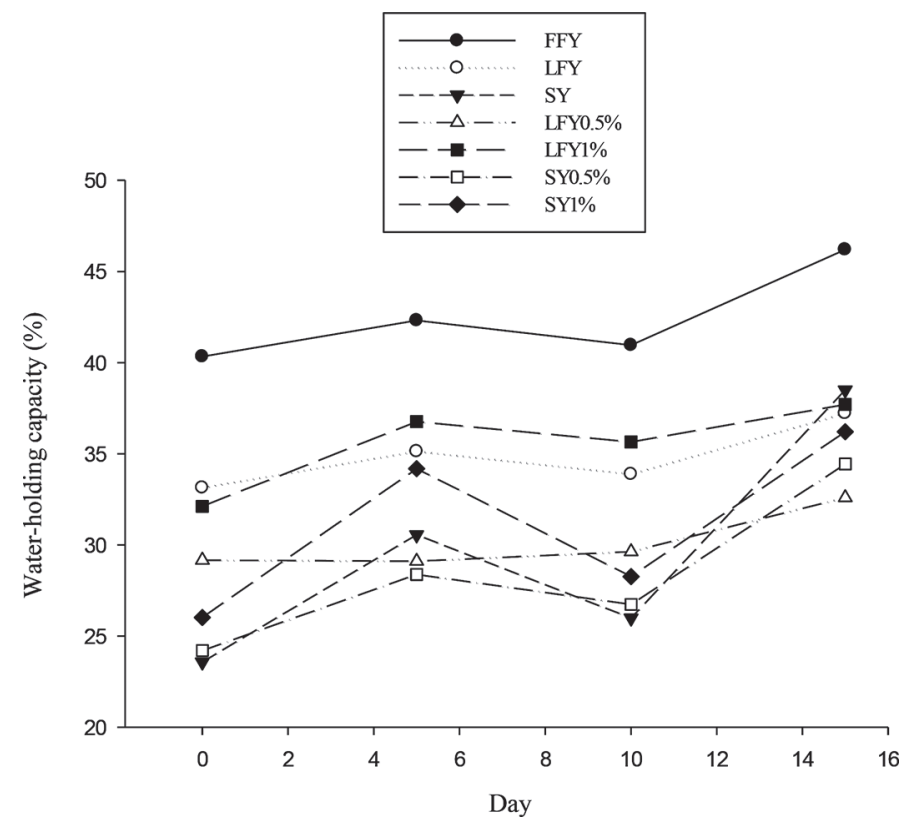

Figure 2. Water-holding capacity (WHC) of yogurts prepared with basil seed gum (BSG) during $15 \mathrm{~d}$ of storage at $4^{\circ} \mathrm{C}$. FFY $=$ full-fat yogurt; LFY = low-fat yogurt; $\mathrm{SY}=$ skimmed yogurt; $\mathrm{LFY} 0.5 \%=$ low-fat yogurt with $0.5 \%$ BSG; LFY $1 \%=$ low-fat yogurt with $1 \%$ BSG; SY 0.5\% = skimmed yogurt with $0.5 \%$ BSG; SY 1\% = skimmed yogurt with $1 \%$ BSG. 
d 0 to 5 and stayed roughly the same from d 5 onward. Achanta et al. (2007) reported that with longer storage time, syneresis increases steadily. The syneresis of FFY and LFY were the lowest and the addition of BSG 0.5\% and BSG $1 \%$ did not have a positive effect on the LFY group at $d$, whereas the addition of BSG $1 \%$ to SY decreased the syneresis of the SY group. Addition of BSG $0.5 \%$ did not decrease the syneresis and addition of BSG $1 \%$ slightly decreased the syneresis of LFY at d 5, 10, and 15. The syneresis of SY was higher than SY $0.5 \%$ and SY $1 \%$ during the storage. The results of other studies on yogurt, where fat was replaced with several ingredients such as glucomannan (Dai et al., 2016) or inulin (Guven et al., 2005), are slightly different from our results. Dai et al. (2016) showed that syneresis significantly decreased in all groups until d 7 compared with that at d 14 to 21 and slightly decreased during storage beyond d 14. Mudgil et al. (2018) in their study on yogurt supplemented with gelatin speculated that the reduction in syneresis is caused by immobilization of the aqueous phase and by greater capacity for building a gel network with casein micelles. Basil seed gum has good gelling properties, which can modify a protein network by acting as a filler and giving finer structure to yogurt (Rafe et al., 2013). The results of our study suggest that the addition of BSG to reducedfat or nonfat yogurt may slightly reduce the syneresis of these yogurts. Furthermore, we found that the addition of BSG at $1 \%$ may decrease syneresis to a level different from that observed with the addition of less than $0.5 \%$ glucomannan (Dai et al., 2016) and 0.5\% inulin (Guven et al., 2005).

\section{Total Phenol Content, Flavonoid Content, and Antioxidant Activity}

Polyphenols possess an ideal structure for scavenging of free radicals and act as more effective antioxidants in vitro than vitamins $\mathrm{E}$ or $\mathrm{C}$, and polyphenols comprise various molecules with numerous phenol structures and several subgroups of phenolic compounds (Jakobek, 2015). Polyphenols are components of yellow, green, red, orange, and purple pigments found in plants and interact with the lipids, proteins, and carbohydrates, thus decreasing lipid absorption and oxidation, and then create an antioxidant environment that prevents the effects of various reactive oxygen species that cause heart disease, stroke, diabetes, gastric ulcer, and immunodeficiency syndrome (Elmastaş et al., 2006). Flavonoids, which are a subgroup of polyphenols, also have a lot of subgroups such as flavanones, anthocyanidins, flavones, and flavonols (Rice-Evans et al., 1996). Duarte et al. (1993) stated that flavonoids, due to their freeradical-scavenging activity, have multiple biological activities such as vasodilatory, anticarcinogenic, immunostimulatory, antiallergic, and glutathione reductase. Antioxidant compounds can donate an electron, react with other antioxidants, chelate a metal ion, and participate in other reactions; for this reason, functional antioxidant compounds can act as anticancer drugs, antimicrobial agents, antiviral compounds against human immunodeficiency virus (HIV), and inhibitors of cyclin-dependent kinases in breast carcinoma cells (Abbas et al., 2017). The results on total contents of phenol and flavonoid are shown in Table 3. There was a significant effect on total contents of phenol and flavonoid when the yogurts were supplemented with BSG as compared with the control groups, and the BSG $1.0 \%$ group had significantly higher total contents of phenol and flavonoid than did the other groups. Total contents of phenol and flavonoid gradually increased with the increasing concentration of BSG. Basil seed gum is known for its high levels of phenolic acids, which contribute to antioxidant activity; for this reason, BSG has been used for the treatment of cough, inflammation, and dyspepsia for a long time and its phenolic content is similar to that of red and black raspberries (Wang and Lin, 2000; Kwee and Niemeyer, 2011). To investigate the antioxidant abilities of fruits, vegetables, and other foods, several assays such as 2,2-azinobis(3ethyl-benzothiazoline-6-sulfonic acid) (Leong and Shui, 2002), 2.2-diphenyl-1-1-picrylhydrazyl (Brand-Williams et al., 1995), FRAP (Benzie and Strain, 1996),

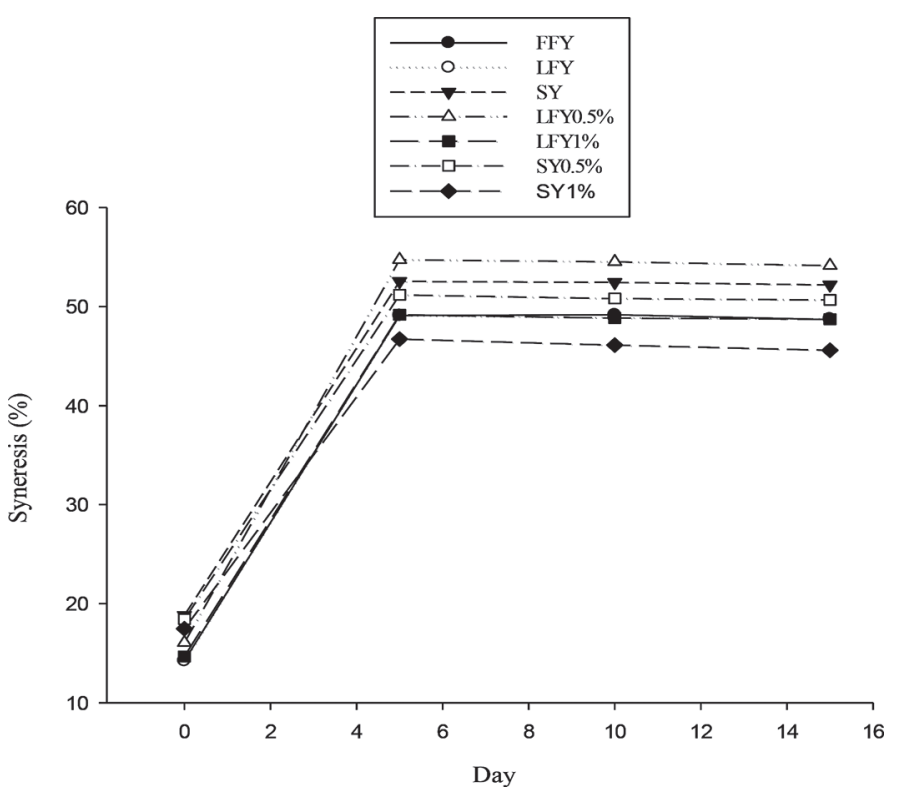

Figure 3. Syneresis of yogurts prepared with basil seed gum (BSG) during $15 \mathrm{~d}$ of storage at $4^{\circ} \mathrm{C}$. FFY $=$ full-fat yogurt; $\mathrm{LFY}=$ low-fat yogurt; SY = skimmed yogurt; LFY $0.5 \%=$ low-fat yogurt with $0.5 \%$ BSG; LFY $1 \%=$ low-fat yogurt with $1 \%$ BSG; SY $0.5 \%=$ skimmed yogurt with $0.5 \%$ BSG; SY $1 \%=$ skimmed yogurt with $1 \%$ BSG. 
and oxygen radical absorption capacity assay (Cao et al., 1996) have been used. Free radicals have 2 main routes: (1) superoxide anion radicals and hydroxyl radical formation from aerobic respiration and (2) exogenous sources such as pollutants, organic solvents, and pesticides (Elmastaş et al., 2006). These kinds of reactive oxygen species, which cause oxidative damage to biomolecules, are removed by the antioxidant defense system of antioxidant compounds (Gülçin et al., 2007). The FRAP method is one of the assays that are designed to measure the antioxidant activity by measuring the changes of color where the yellow color of the test solution changes to various shades of green and blue colors depending upon the reducing power of each samples and is detected at $700 \mathrm{~nm}$ (Chung et al., 2002). Similar to the results on total contents of phenol and flavonoid, the highest reducing power was seen in the BSG-supplemented group. Juliani and Simon (2002) reported that the antioxidant capacity of basil seed is strongly related to the phenolic components of basil seed, and this capacity was proved by the FRAP assay. The results on antioxidant activity indicate that BSG addition enhanced the antioxidant activity. This difference in antioxidant activity among the BSG-added group and control group were due to the total phenolic compounds of BSG.

\section{Sensory Evaluation}

Seven yogurt samples (FFY, LFY, SY, LFY with 0.5 or $1 \%$ BSG, and SY with 0.5 or $1 \%$ BSG) were prepared for the sensory evaluation conducted by 40 untrained panelists. Janiaski et al. (2016) reported that the sensory properties of food are strongly related to consumer preferences and determine product acceptability; this phenomenon can help to optimize a recipe. The results of the sensory evaluation of yogurt samples are shown in Table 4. The sensory attributes of yogurt were categorized as follows: appearance and color, flavor, texture, sourness, and overall acceptability. The appearance is perceived visually, and the most important parameter is color, which is determined by the degree of reflection and absorption of light that occurs when the food comes into contact with the radiated energy of 380 to $770 \mathrm{~nm}$ wavelength; color assessment involves such parameters as lightness, hue, and chroma ( $\mathrm{Gu}$ et al., 2014). Besides, the surface is evaluated by smoothness, shape, and texture. The FFY received the best scores in all categories evaluated among the samples. The highest scores for appearance and color, texture, and overall acceptability were assigned to FFY. The slightly higher texture score of the BSG-supplemented yogurt may reflect the increased viscosity of yogurt judging by instrumental analysis. The parameter used to measure

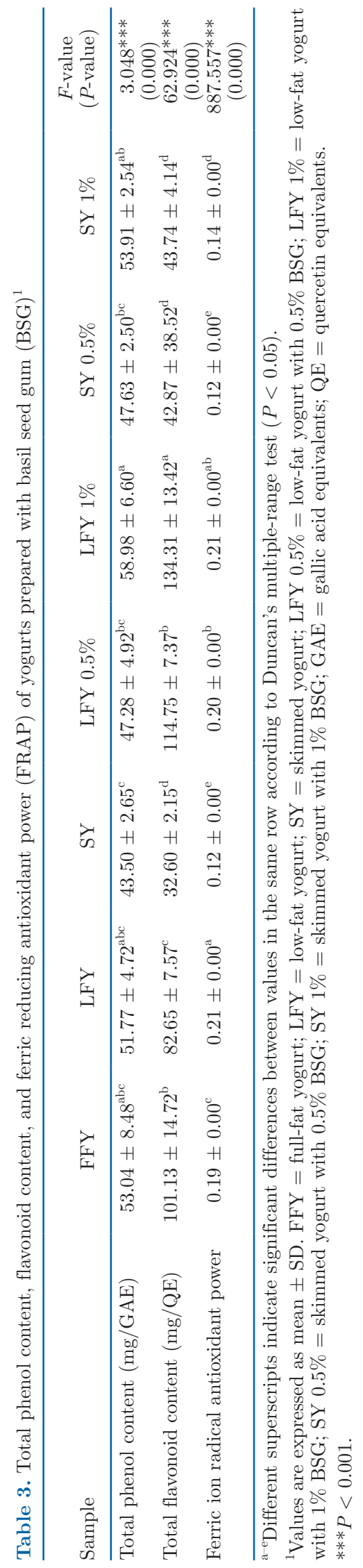


texture of yogurt is viscosity, which is the magnitude of the resistance to flow [i.e., the force required to draw food into the mouth (Gu et al., 2014)]. These results are similar to the findings about the addition of gelatin (Mudgil et al., 2018) to yogurts; namely, yogurts supplemented with gelatin have a higher score than control in terms of texture and overall acceptance. In contrast to our study, Guggisberg et al. (2009) concluded that addition of inulin has no significant effect on textural properties of yogurt, on the basis of rheological data where an increase in viscosity was not definitively proved. The flavor was the highest in FFY and lowest in LFY $0.5 \%$, but at a concentration of BSG $1 \%$, flavor was improved compared with the control group of LFY. The sourness was highest in FFY and lowest in SY. The addition of BSG to SY increased the preference of sourness. Additionally, between the SY samples, as the concentration of BSG increased, the flavor, texture, and overall acceptability were improved compared with the SY group. These results contradict the findings about the addition of gelatin (Mudgil et al., 2018) to yogurt where gelatin adversely affected the taste and flavor. Flavor, which is detected by the combined action of taste buds and olfactory receptors, is strongly related to preferences regarding food and quality properties (Gu et al., 2014). The sour taste is due to the dissociated hydrogen ions in a solution and to the salt of an undissociated acid; thus, the intensity of sourness does not necessarily coincide with the hydrogen ion concentration but depends on total acidity (Gu et al., 2014). The reduction in fat content significantly influenced the sensory perception of the yogurt samples and addition of BSG had a positive effect on sensory properties. The relatively small size of our panel (40 people) is the limitation of this study. Nevertheless, our findings may serve as preliminary sensory data for applying BSG to food as a fat substitute substance.

\section{CONCLUSIONS}

The aim of this study was to investigate the effects of BSG as a fat substitute substance in reduced-fat and nonfat yogurt. This study demonstrated that substitution of fat with BSG in yogurt can have a positive effect on gel network formation, resulting in increased viscosity and WHC and decreased syneresis. Furthermore, the supplementation of BSG had a strong effect on antioxidant activity and sensory characteristics. It was concluded that optimal results are obtained by adding BSG to reduced-fat or nonfat yogurt at a concentration of $1 \%$. This study may help producers of reduced-fat or nonfat dairy to improve the quality properties, nutritional value, and sensory properties of dairy products. The issue of low acceptance of reduced-

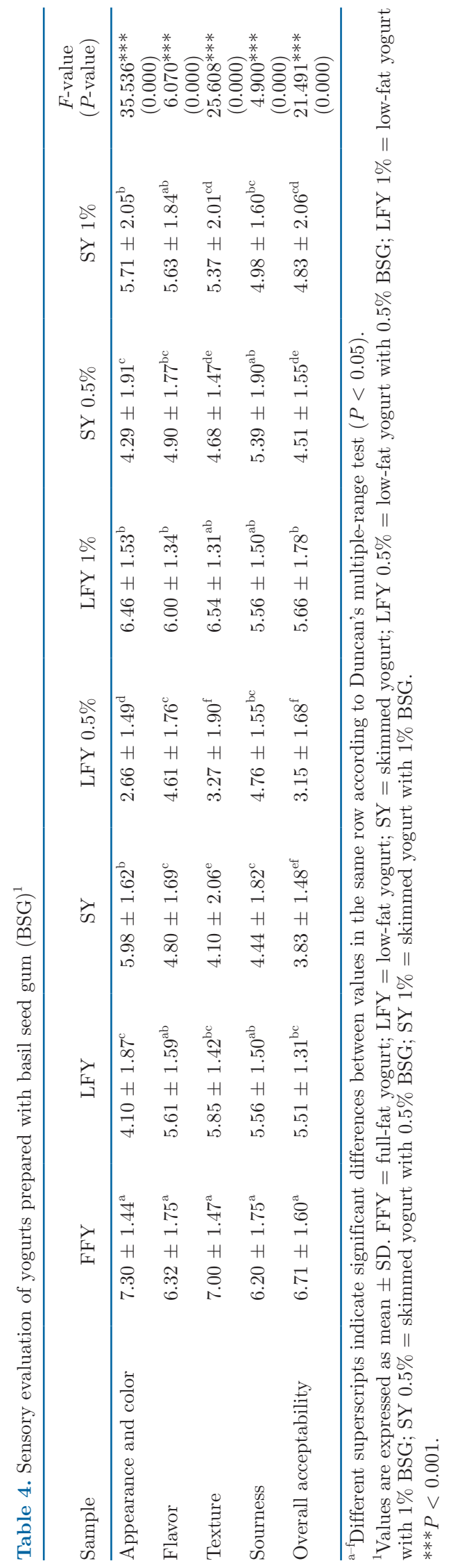


fat and nonfat yogurts, which are inferior with respect to taste and texture, can be improved by adding some fat substitutes to yogurt, and BSG could be one of the new natural hydrocolloids acting as a fat substitute substance in yogurt. Further research is needed to investigate the effects of BSG and apply it to various foods as a fat substitute substance to enhance overall quality parameters of reduced-fat and nonfat yogurt.

\section{ACKNOWLEDGMENTS}

This research did not receive any specific grant from funding agencies in the public, commercial, or not-forprofit sectors.

\section{REFERENCES}

Abbas, M., F. Saeed, F. M. Anjum, M. Afzaal, T. Tufail, M. S. Bashir, A. Ishtiaq, S. Hussain, and H. A. R. Suleria. 2017. Natural polyphenols: An overview. Int. J. Food Prop. 20:1689-1699. https://doi .org/10.1080/10942912.2016.1220393.

Achanta, K., K. J. Aryana, and C. A. Boeneke. 2007. Fat free plain set yogurts fortified with various minerals. LWT-Food Sci. Technol. 40:424-429.

Akay, S., I. Alpak, and O. Yesil-Celiktas. 2011. Effects of process parameters on supercritical $\mathrm{CO}_{2}$ extraction of total phenols from strawberry (Arbutus unedo L.) fruits: An optimization study. J. Sep. Sci. 34:1925-1931. https://doi.org/10.1002/jssc.201100361.

Akgun, A., F. Yazici, and H. A. Gulec. 2016. Effect of reduced fat content on the physicochemical and microbiological properties of buffalo milk yoghurt. LWT 74:521-527. https://doi.org/10.1016/ j.lwt.2016.08.015.

Amatayakul, T., F. Sherkat, and N. P. Shah. 2006. Syneresis in set yogurt as affected by EPS starter cultures and levels of solids. Int. J. Dairy Technol. 59:216-221. https://doi.org/10.1111/j.1471-0307 2006.00264.x.

AOAC. 1990. Official Methods of Analysis. Vol. I. 15th ed. AOAC International, Washington, DC.

Arancibia, C., E. Costell, and S. Bayarri. 2011. Fat replacers in lowfat carboxymethyl cellulose dairy beverages: Color, rheology, and consumer perception. J. Dairy Sci. 94:2245-2258. https://doi.org/ 10.3168/jds.2010-3989.

Aziznia, S., A. Khosrowshahi, A. Madadlou, and J. Rahimi. 2008. Whey protein concentrate and gum tragacanth as fat replacers in nonfat yogurt: Chemical, physical, and microstructural properties. J. Dairy Sci. 91:2545-2552. https://doi.org/10.3168/jds.2007 -0875 .

Becerir, B. 2017. Color concept in textile: A review. J. Text. Eng. Fashion Technol. 1:240-244. https://doi.org/10.15406/jteft.2017 .01 .00039 .

Benzie, I. F., and J. J. Strain. 1996. The ferric reducing ability of plasma (FRAP) as a measure of "antioxidant power": The FRAP assay. Anal. Biochem. 239:70-76. https://doi.org/10.1006/abio .1996 .0292

Brand-Williams, W., M. E. Cuvelier, and C. L. W. T. Berset. 1995. Use of a free radical method to evaluate antioxidant activity. Lebensm. Wiss. Technol. 28:25-30. https://doi.org/10.1016/S0023 $-6438(95) 80008-5$.

Brennan, C. S., and C. M. Tudorica. 2008. Carbohydrate-based fat replacers in the modification of the rheological, textural and sensory quality of yoghurt: Comparative study of the utilisation of barley beta-glucan, guar gum and inulin. Int. J. Food Sci. Technol. 43:824-833. https://doi.org/10.1111/j.1365-2621.2007.01522.x.

Cao, G., E. Sofic, and R. L. Prior. 1996. Antioxidant capacity of tea and common vegetables. J. Agric. Food Chem. 44:3426-3431. https://doi.org/10.1021/jf9602535.
Chung, Y. C., C. T. Chang, W. W. Chao, C. F. Lin, and S. T. Chou. 2002. Antioxidative activity and safety of the 50 ethanolic extract from red bean fermented by Bacillus subtilis IMR-NK1. J. Agric. Food Chem. 50:2454-2458. https://doi.org/10.1021/jf011369q.

Coorey, R., A. Tjoe, and V. Jayasena. 2014. Gelling properties of chia seed and flour. J. Food Sci. 79:E859-E866. https://doi.org/10 $.1111 / 1750-3841.12444$.

Dai, S., H. Corke, and N. P. Shah. 2016. Utilization of konjac glucomannan as a fat replacer in low-fat and skimmed yogurt. J. Dairy Sci. 99:7063-7074. https://doi.org/10.3168/jds.2016-11131.

Duarte, J., F. P. Vizcaíno, P. Utrilla, J. Jiménez, J. Tamargo, and A. Zarzuelo. 1993. Vasodilatory effects of flavonoids in rat aortic smooth muscle. Structure-activity relationships. Gen. Pharmacol. 24:857-862. https://doi.org/10.1016/0306-3623(93)90159-U.

Elmastaş, M., I. Gülçin, Ö. M. E. R. Işildak, Ö. İ. Küfrevioğlu, K. İbaoğlu, and H. Y. Aboul-Enein. 2006. Radical scavenging activity and antioxidant capacity of bay leaf extracts. J. Iranian Chem. Soc. 3:258-266. https://doi.org/10.1007/BF03247217.

Emadzadeh, B., S. M. A. Razavi, E. Rezvani, and G. Schleining. 2015. Steady shear rheological behavior and thixotropy of low-calorie pistachio butter. Int. J. Food Prop. 18:137-148. https://doi.org/10 $.1080 / 10942912.2013 .822882$.

Fu, R., J. Li, T. Zhang, T. Zhu, R. Cheng, S. Wang, and J. Zhang. 2018. Salecan stabilizes the microstructure and improves the rheological performance of yogurt. Food Hydrocoll. 81:474-480. https: //doi.org/10.1016/j.foodhyd.2018.03.034.

Gu, N. S., H. S. Kim, K. Lee, and M. J. Kim. 2014. Sensory evaluation theory and experiment. Pages 15-48 in Sensory Evaluation. Vol. 1. Gyomoon. Paju, Korea.

Guggisberg, D., J. Cuthbert-Steven, P. Piccinali, U. Bütikofer, and P. Eberhard. 2009. Rheological, microstructural and sensory characterization of low-fat and whole milk set yoghurt as influenced by inulin addition. Int. Dairy J. 19:107-115. https://doi.org/10.1016/ j.idairyj.2008.07.009.

Gülçin, İ., M. Elmastaş, and H. Y. Aboul-Enein. 2007. Determination of antioxidant and radical scavenging activity of Basil (Ocimum basilicum L. Family Lamiaceae) assayed by different methodologies. Phytother. Res. 21:354-361. https://doi.org/10.1002/ptr 2069 .

Guven, M., K. Yasar, O. B. Karaca, and A. A. Hayaloglu. 2005. The effect of inulin as a fat replacer on the quality of set-type low-fat yogurt manufacture. Int. J. Dairy Technol. 58:180-184. https://doi .org/10.1111/j.1471-0307.2005.00210.x.

Hosseini-Parvar, S. H., L. Matia-Merino, K. K. T. Goh, S. M. A. Razavi, and S. A. Mortazavi. 2010. Steady shear flow behavior of gum extracted from Ocimum basilicum L. seed: Effect of concentration and temperature. J. Food Eng. 101:236-243. https://doi.org/10 .1016/j.jfoodeng.2010.06.025.

Imam, H., S. Lian, R. Kasimu, R. K. Rakhmanberdyeva, and H. A. Aisa. 2012. Extraction of an antidiabetic polysaccharide from seeds of Ocimum basilicum and determination of the monosaccharide composition by precolumn high-efficiency capillary electrophoresis. Chem. Nat. Compd. 48:653-654. https://doi.org/10 .1007/s10600-012-0336-8.

Jakobek, L. 2015. Interactions of polyphenols with carbohydrates, lipids and proteins. Food Chem. 175:556-567. https://doi.org/10 .1016/j.foodchem.2014.12.013.

Janiaski, D. R., T. C. Pimentel, A. G. Cruz, and S. H. Prudencio. 2016. Strawberry-flavored yogurts and whey beverages: What is the sensory profile of the ideal product? J. Dairy Sci. 99:52735283. https://doi.org/10.3168/jds.2015-10097.

Javidi, F., S. M. Razavi, F. Behrouzian, and A. Alghooneh. 2016. The influence of basil seed gum, guar gum and their blend on the rheological, physical and sensory properties of low fat ice cream. Food Hydrocoll. 52:625-633. https://doi.org/10.1016/j.foodhyd.2015.08 .006 .

Jenness, R., and S. Patton. 1959. Principles of Dairy Chemistry. John Wiley, New York, NY.

Juliani, H. R., and J. E. Simon. 2002. Antioxidant activity of basil. Pages 575-579 in Trends in New Crops and New Uses. J. Janick and A. Whipkey, ed. ASHS Press, Alexandria, VA. 
Kadam, P. V., K. N. Yadav, S. K. Jagdale, R. S. Shivatare, S. K. Bhilwade, and M. J. Patil. 2012. Evaluation of Ocimum sanctum and Ocimum basilicum mucilage-as a pharmaceutical excipient. J. Chem. Pharm. Res. 4:1950-1955.

Karthikeyan, K., P. Gunasekaran, N. Ramamurthy, and S. Govindasamy. 1999. Anticancer activity of Ocimum sanctum. Pharm. Biol. 37:285-290. https://doi.org/10.1076/phbi.37.4.285.5801.

Kwee, E. M., and E. D. Niemeyer. 2011. Variations in phenolic composition and antioxidant properties among 15 basil (Ocimum basilicum L.) cultivars. Food Chem. 128:1044-1050. https://doi.org/10 $.1016 /$ j.foodchem.2011.04.011.

Laiho, S., R. P. W. Williams, A. Poelman, I. Appelqvist, and A. Logan. 2017. Effect of whey protein phase volume on the tribology, rheology and sensory properties of fat-free stirred yoghurts. Food Hydrocoll. 67:166-177. https://doi.org/10.1016/j.foodhyd.2017.01 .017 .

Lee, M. J., Y. K. Kim, K. H. Kim, and N. Y. Lee. 2015. Quality characteristics of whole barley flour added to yogurt during storage. Food Eng. Prog. 19:8-13. https://doi.org/10.13050/foodengprog .2015.19.1.8.

Lee, W. J., and J. A. Lucey. 2010. Formation and physical properties of yogurt. J. Anim. Sci. 23:1127-1136.

Leong, L. P., and G. Shui. 2002. An investigation of antioxidant capacity of fruits in Singapore markets. Food Chem. 76:69-75. https:// doi.org/10.1016/S0308-8146(01)00251-5.

Lucey, J. A., P. A. Munro, and H. Singh. 1998. Whey separation in acid milk gels made with glucono-delta-lactone: Effects of heat treatment and gelation temperature. J. Texture Stud. 29:413-426. https://doi.org/10.1111/j.1745-4603.1998.tb00813.x.

Madadlou, A., A. Khosroshahi, and M. E. Mousavi. 2005. Rheology, microstructure, and functionality of reduced-fat Iranian white cheese made with different concentrations of rennet. J. Dairy Sci. 88:3052-3062. https://doi.org/10.3168/jds.S0022-0302(05)72986 $-6$.

Milani, E., and A. Koocheki. 2011. The effects of date syrup and guar gum on physical, rheological and sensory properties of low fat frozen yoghurt dessert. Int. J. Dairy Technol. 64:121-129. https://doi .org/10.1111/j.1471-0307.2010.00631.x.

Mistry, V. V., and H. N. Hassan. 1992. Manufacture of nonfat yogurt from a high milk protein powder. J. Dairy Sci. 75:947-957. https:/ /doi.org/10.3168/jds.S0022-0302(92)77835-7.

Mudgil, P., B. Jumah, M. Ahmad, F. Hamed, and S. Maqsood. 2018. Rheological, micro-structural and sensorial properties of camel milk yogurt as influenced by gelatin. LWT 98:646-653. https://doi .org/10.1016/j.lwt.2018.09.008.

Naji-Tabasi, S., and S. M. A. Razavi. 2016. New studies on basil (Ocimum basilicum L.) seed gum: Part II-Emulsifying and foaming characterization. Carbohydr. Polym. 49:40-150.

Naji-Tabasi, S., and S. M. A. Razavi. 2017a. Functional properties and applications of basil seed gum: An overview. Food Hydrocoll. 73:313-325. https://doi.org/10.1016/j.foodhyd.2017.07.007.

Naji-Tabasi, S., and S. M. A. Razavi. 2017b. New studies on basil (Ocimum basilicum L.) seed gum: Part III-Steady and dynamic shear rheology. Food Hydrocoll. 67:243-250. https://doi.org/10 $.1016 / \mathrm{j}$.foodhyd.2015.12.020

Naji-Tabasi, S., S. M. A. Razavi, M. Mohebbi, and B. MalaekehNikouei. 2016. New studies on basil (Ocimum basilicum L.) seed gum: Part I-Fractionation, physicochemical and surface activity characterization. Food Hydrocoll. 52:350-358. https://doi.org/10 .1016/j.foodhyd.2015.07.011

Nimeroff, I. 1968. Colorimetry. National Bureau of Standards Monograph, Washington, DC.

Olivares, M. L., K. Shahrivar, and J. de Vicente. 2019. Soft lubrication characteristics of microparticulated whey proteins used as fat replacers in dairy systems. J. Food Eng. 245:157-165. https://doi .org/10.1016/j.jfoodeng.2018.10.015.

Osano, J. P., S. H. Hosseini-Parvar, L. Matia-Merino, and M. Golding. 2014. Emulsifying properties of a novel polysaccharide extracted from basil seed (Ocimum bacilicum L.): Effect of polysaccharide and protein content. Food Hydrocoll. 37:40-48.

Rafe, A., S. M. Razavi, and R. Farhoosh. 2013. Rheology and microstructure of basil seed gum and $\beta$-lactoglobulin mixed gels. Food
Hydrocoll. 30:134-142. https://doi.org/10.1016/j.foodhyd.2012.05 .016 .

Ramchandran, L., and N. P. Shah. 2009. Effect of exopolysaccharides on the proteolytic and angiotensin-I converting enzyme-inhibitory activities and textural and rheological properties of low-fat yogurt during refrigerated storage. J. Dairy Sci. 92:895-906.

Rasic, J. L., and J. A. Kurmann. 1978. Yoghurt: Scientific Grounds, Technology, Manufacture and Preparations. Technical Dairy Publishing House, Copenhagen, Denmark.

Razavi, S. M., S. A. Mortazavi, L. Matia-Merino, S. H. Hosseini-Parvar, A. Motamedzadegan, and E. Khanipour. 2009. Optimisation study of gum extraction from Basil seeds (Ocimum basilicum L.). Int. J. Food Sci. Technol. 44:1755-1762. https://doi.org/10.1111/j .1365-2621.2009.01993.x.

Razavi, S., and S. Naji-Tabasi. 2017. Rheology and texture of basil seed gum: A new hydrocolloid source. Pages 405-435 in Advances in Food Rheology and Its Applications. J. Ahmed, P. Ptaszek, and S. Basu, ed. Elsevier, Amsterdam, the Netherlands.

Razavi, S. M. A., S. Shamsaei, S. E. Ataye, and B. Emadzadeh. 2012. Effect of basil seed gum and xanthan gum as fat substitute substances on the characteristics of reduced fat mayonnaise. J. Food Sci. Technol. 13:101-108.

Rice-Evans, C. A., N. J. Miller, and G. Paganga. 1996. Structureantioxidant activity relationships of flavonoids and phenolic acids. Free Radic. Biol. Med. 20:933-956. https://doi.org/10.1016/0891 $-5849(95) 02227-9$

Sahan, N., K. Yasar, and A. A. Hayaloglu. 2008. Physical, chemical and flavour quality of non-fat yogurt as affected by a $\beta$-glucan hydrocolloidal composite during storage. Food Hydrocoll. 22:12911297. https://doi.org/10.1016/j.foodhyd.2007.06.010.

Sandoval-Castilla, O., C. Lobato-Calleros, E. Aguirre-Mandujano, and E. J. Vernon-Carter. 2004. Microstructure and texture of yogurt as influenced by fat replacers. Int. Dairy J. 14:151-159. https://doi .org/10.1016/S0958-6946(03)00166-3.

Sandrou, D. K., and I. S. Arvanitoyannis. 2000. Reduced-fat/calorie foods: Current state and perspectives. Crit. Rev. Food Sci. Nutr. 40:427-447. https://doi.org/10.1080/10408690091189211.

Shihata, A., and N. P. Shah. 2002. Influence of addition of proteolytic strains of Lactobacillus delbrueckii ssp. bulgaricus to commercial ABT starter cultures on texture of yoghurt, exopolysaccharide production and survival of bacteria. Int. Dairy J. 12:765-772. https://doi.org/10.1016/S0958-6946(02)00071-7.

Song, K.-Y. O. H., Y. Zhang, K. Y. Joung, D. W. Choi, and Y. S. Kim. 2017. Effect of black carrot (Daucus carota L.) powder on quality characteristics and retarding retrogradation by shelf-life of Sulgidduck (rice cake). Prog. Nutr. 19:442-449.

Tamime, A. Y., and H. C. Deeth. 1980. Yogurt: Technology and biochemistry. J. Food Prot. 43:939-977. https://doi.org/10.4315/0362 $-028 \mathrm{X}-43.12 .939$.

Tamime, A. Y., and R. K. Robinson. 1999. Yoghurt: Science and Technology, 2nd ed. Woodhead Publishing Ltd., Cambridge, UK.

Tamime, A. Y., and R. K. Robinson. 2007. Yogurt: Science and Technology, 3rd ed. CRC Press, New York, NY.

Verbeke, W. 2006. Functional foods: Consumer willingness to compromise on taste for health? Food Qual. Prefer. 17:126-131. https:// doi.org/10.1016/j.foodqual.2005.03.003.

Vosoughi, N., M. Gomarian, A. G. Pirbalouti, S. Khaghani, and F. Malekapoor. 2018. Essential oil composition and total phenolic, flavonoid contents, and antioxidant activity of sage (Salvia officinalis L.) extract under chitosan application and irrigation frequencies. Ind. Crops Prod. 117:366-374. https://doi.org/10.1016/ j.indcrop.2018.03.021.

Wang, S. Y., and H. S. Lin. 2000. Antioxidant activity in fruits and leaves of blackberry, raspberry, and strawberry varies with cultivar and developmental stage. J. Agric. Food Chem. 48:140-146. https: //doi.org/10.1021/jf9908345.

Yazici, F., and A. Akgun. 2004. Effect of some protein based fat replacers on physical, chemical, textural, and sensory properties of strained yoghurt. J. Food Eng. 62:245-254. https://doi.org/10 .1016/S0260-8774(03)00237-1 